\title{
The Rivalry Between Sugar Beets and Sugar Cane
}

\section{Ellsworth Huntington \& Sumner W. Cushing}

To cite this article: Ellsworth Huntington \& Sumner W. Cushing (1920) The Rivalry Between Sugar Beets and Sugar Cane, Journal of Geography, 19:7, 255-259, DOI: 10.1080/00221342008984891

To link to this article: http://dx.doi.org/10.1080/00221342008984891

曲 Published online: 22 Feb 2008.

Submit your article to this journal $\pi$

Џ Article views: 4

Q View related articles ¿ 


\section{THE RIVALRY BETWEEN SUGAR BEETS AND SUGAR CANE $^{1}$}

\section{By ELLSWORTH HUNTINGTON and SUMNER W. CUSHING}

A few centuries ago people satisfied their need for sugar by occasionally eating honey, by drinking the sap of such trees as the maple and palm, or by chewing a stick of sugar cane. Now all civilized people use pure sugar and plenty of it three times a day in various food and drinks. Hence, it pays for hundreds of thousands of farmers to raise plants just for the sugar they contain. Sugar beets and sugar maples are raised in cold regions, sugar cane in warm regions, and sorghum cane in intermediate regions. By far the most important of these are sugar cane and sugar beets. Only those who use sugar in preserving fruits, or making candy can tell the difference between the sugar made from beets and that made from cane.

A sugar cane looks like a corn stalk without the ears. It grows differently, however, for many canes spring from one root, and when they are cut new shoots begin to sprout from the old root. A sorghum cane also looks somewhat like a corn stalk and grows in the same way. The sugar beet looks like a rutabaga turnip in color, size, and shape. It has been carefully developed for nearly a century by selecting year after year the seeds of those beets that are sweetest. Eighty years ago it took eighteen pounds of beets to yield one pound of sugar, while now only six pounds are needed.

The United States extends so far from north to south that all four sugar plants are grown within its limits - maple, beets, sorghum, and cane. The accompanying map shows where the three most important grow. Notice that the sugar beet is grown in the cool northern states, the cool plateau states of the west and the cool Pacific coast, while sugar cane is confined to the warm southern states. Sorghum does well in the cooler parts of the southern states, between the beet and the cane. The delicious maple sugar is taken from trees in our northernmost states from Indiana eastward and in southern Canada.

\section{Sugar BeEts}

Sugar beets could be grown much more extensively in the United States but they are crowded out by more profitable crops such as

1 This is a chapter from a "Commercial and Industrial Geography" for junior high schools, to be published shortly by the World Book Company.-Editor. 
cereals. They are not adapted to American methods of agriculture because they require much hand labor. No machines have as yet been invented for weeding the young plants and thinning them out. Women and children usually do this tiresome work, for it must be done cheaply or not at all.

Because the better soil is used for more profitable crops beets are often crowded on to sandy soil where little else will grow. This is the reason eastern Michigan is so prominent in the beet industry. But the best place for beets, as appears on the map, is in the irrigated lands of the dry West where the cool, but sunny weather of the long autumn causes the beets to grow large and sugary. This is why Colorado, California, Utah, and Idaho, are important producers of beet sugar.

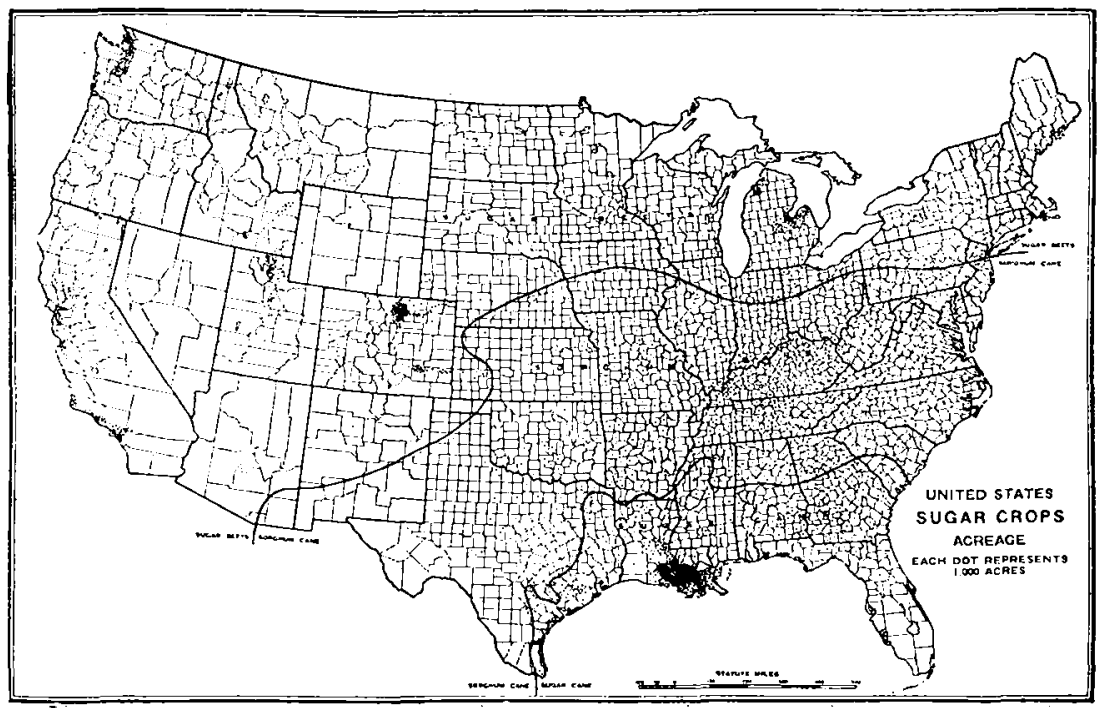

Distribution of Acreage of Sugar Crops in the United States. - From Finch and Baker. Gengraphy of the World's Agriculture.

In these states throughout the winter months large factories receive a constant stream of wagons and trains, bearing the best of the beet crop. There they are washed, sliced, and soaked in hot water to take out the juice. The juice is partly purified with lime and acid, and then filtered. Next it is heated until the water evaporates leaving the sugar as damp brownish crystals. These are purified, whitened, and broken into the granulated table sugar we know so well.

\section{Sugar Befts Outside of the United States}

The cool climate with moderate summer rainfall and dry sunny autumns in which sugar beets thrive is found throughout northern 
Europe from northern France to central Russia. Beets are an especially important crop in central Germany and Bohemia. This is partly because farm labor is cheap and partly because the population is so dense that there is not room for pasturage and the people find it profitable to feed their cattle with the pulp that is left after the sugar has been extracted from the beets. Moreover, there is a large market for sugar close at hand, and the great sugar cane regions are far away.

No wonder the summer traveller in northern Europe long remembers the great expanses of beet fields, and the peasant women and children on their knees pulling the weeds that would smother the young-plants.

\section{Sugar Cane}

Happy are the boys and girls who live on a sugar cane plantation! Nature's stick of candy, a piece of sugar cane, can be had at any time for the cutting. Moreover, it can be chewed and sucked much longer than an ordinary stick of candy, and will still taste delightfully sweet. The boys and girls who would enjoy this happy experience must betake themselves to warm regions.

The coolest places where the sugar cane grows are our southern states, from eastern Texas to South Carolina as appears on the map, but the frosts kill it each winter. This difficulty is overcome by planting new canes every year after the last frost of the winter and harvesting them before the first frost of the next winter. To follow this method successfully requires at least eight months without frost. Nearer to the equator in such places as the great sugar cane islands of the West Indies, Java, Hawaii, and Mauritius, the cane is allowed to grow from three to ten years before new plantings are made and a heavy crop is cut from the plantation every year.

In these islands and in sugar cane regions of lesser importance, such as India, Egypt, Brazil, Northern Argentina, and the Philippines, high uniform temperature prevails and the rainfall is abundant. Under these conditions the cane seems to draw a flood of sweetness from the sun and out of the fertile soil. Sometimes as much as eight tons of sugar are made from the cane cut annually from one acre of land.

In Cuba, where cane sugar is king, the plantations are of great extent and the methods of cultivation and harvesting are very progressive. Often a plantation covers several thousand acres. Gang plows are sometimes used to prepare the soil. As soon as the cane cuttings are set out they quickly give off sprouts. Cultivators drawn by horses are used to keep down the weeds. When the cane stalks 
reach a height of from 6 to 12 feet, men with long heavy knives pass through the rows and strike down the ripe canes at a single blow. The crop of enormous weight is carried to the factory by means of many miles of light moveable railways made in short sections about 8 or 10 feet long. As soon as one part of the plantation is harvested the railway is quickly taken up and put down again elsewhere. In the factory the juice is crushed out of the cane by rollers, and is then heated in huge boilers which thicken the syrup and crystallize the sugar. When sugar is first crystallized it is brown. In this form it is sent to American coast cities, Boston, New York, Philadelphia, Baltimore, New Orleans, San Francisco, where it is refined not only to tickle our palates, but to please our eyes by its whiteness.

\section{Sorghum Cane}

Sorghum is often called Chinese sugar cane because it resembles sugar cane and has long been grown in China. We hear little about it in this country unless we happen to live in the sorghum cane belt shown on the map. The reason is that it is grown merely to satisfy local needs. Most of it is made into molasses which is eaten on corn mush or corn pone. Sorghum is hardier than sugar cane and requires only five and one-half months without frost. It is not so profitable as sugar cane, but its molasses or sugar is more easily extracted than in the case of sugar beets.

\section{QUESTIONS, EXERCISES AND PROBLEMS}

I. To find out what kind of sugar is best produced in various parts of the United States.

A. From the map name the eight leading sugar beet states of the United States. In which of these are the beets raised by irrigation?

What special advantages have these states?

What special advantage have the states bordering the Great Lakes?

B. Name from west to east the states that grow the American cane crop. Cane seems to grow best in the low flood plains and deltas of rivers, not far from the salt water. What relation has this to the state that raises the most cane sugar? Why can Cuba grow cane cheaper than Louisiana?

C. What section of the country, and especially what four states, grow sorghum? Why do we not hear of it in other sections?

II. The annual consumption of sugar in the United States is about 85 pounds per person. This country has ample land, good soil and the proper climate for raising beets and cane in sufficient quantity to yield all the sugar we neect. 
A. Why then should the domestic supply of sugar raised by our whole country be only a fourth of our total consumption, while the little islands of Porto Rico and Hawaii supply an equal amount? Why should Cuba supply nearly half of what we import from foreign countries? Cuban sugar pay's a duty $20 \%$ less than that paid by other foreign sugar. What effect does this have on sugar farmers in Cuba compared with those of Porto Rico, Hawaii and Germany?

III. To find out how various regions are affected by the demand for sugar.

A. In 1836 it took 18 pounds of beets to make one pound of sugar; in 1882 it took ten pounds; and now, about six. How do you suppose farmers have so much increased the sweetness of the beets? Where has this been done to the greatest extent?

B. Today the sugar consumption of the United States is ten times as great as it was a century ago. Account for this increased supply in two ways besides the one just given.

IV. How the United States ekes out its sugar crops.

The demand for sugar is so great and has been increased so much by prohibition that cane and beets do not furnish all that is needed.

A. Each year we use 45 million pounds of sugar extracted from grapes. What effect did the prohibition amendment have upon the production of this sugar? In what states was this most important?

B. Glucose, a by-product of corn, which was formerly wasted, furnishes the country with about $170,000,000$ pounds of sweetness a year. Most of this variety of sugar is consumed by the bakeries and candy makers because it is relatively cheap. In what four states would you expect to find many glucose factories, judging by the production of corn?

C. Our country's yield of honey could be increased about ten times if bee-keeping were to become more general. The flowers of alfalfa, buckwheat, and cotton furnish excellent food for bees. Name three states where much honey might be produced with the aid of each of these.

V. How war affects sugar.

Napoleon is responsible for the development of the beet sugar industry. Because England's blockade had cut off his cane sugar supply, he offered a prize to the man who would make it practicable to supply his army with sugar from beets.

A. Did the English blockade of the German ports in the Great War cause a similar dearth of sugar in Germany? Explain.

B. England was not blockaded, yet it suffered for lack of sugar. What former supplies was it unable to secure? Why?

C. What connection was there between England's inability to secure sugar from its regular source and our sugar shortage?

D. Beet sugar is a crop which yields quick returns and consequently aids greatly in increasing a country's wealth. Explain why the recuperating European nations are raising sugar beets. 